\title{
Urolithiasis: Diagnostic and Therapeutic Aspects in Urology Department of N’Djamena in Chad
}

\author{
Kimassoum Rimtebaye1, Franklin Danki Sillong2, Arya Zarif Agah Tashkand", \\ Mignagnal Kaboro', Lamine Niang ${ }^{3}$, Serigne Magueye Gueye ${ }^{3}$ \\ ${ }^{1}$ National General Referral Hospital of N'Djamena, N'Djamena, Chad \\ ${ }^{2}$ Prostestant Hospital of N'Gaoundéré, N'Gaoundéré, Cameroon \\ ${ }^{3}$ General Hospital of Grand Yoff of Dakar, Dakar, Senegal \\ Email: melinarim@yahoo.fr
}

Received 27 September 2015; accepted 7 November 2015; published 11 November 2015

Copyright (C) 2015 by authors and Scientific Research Publishing Inc.

This work is licensed under the Creative Commons Attribution International License (CC BY). http://creativecommons.org/licenses/by/4.0/

(c) (i) Open Access

\begin{abstract}
Introduction: To study the clinical, paraclinical, diagnostic aspects and manage patients with urolithiasis according to the available technical facilities in urology department of N'Djamena in Chad. Urolithiasis is defined as the presence of one or more stony concretions located at any level of a segment of the urinary tract: calyx, renal pelvis, ureters, bladder and urethra. Materials and Methods: This was a descriptive type of a prospective study over a period of 4 years, from January 2008 to December 2011, involving 233 patients with urolithiasis treated in the urology department. Clinical and paraclinical examinations were the basis for the selection of patients. Informed consent of patient or their parents (for minors) was obtained for the anonymous use of records and photographs for scientific aims. Results: Urolithiasis represented $5.72 \%(233 / 4072)$ of all urological pathologies. Male dominance was significant with a sex ratio of $4.5 / 1$. The age group of 0 - 10 years was the most affected with a staff of $67(28.75 \%)$. The clinic was dominated by dysuria (44.63\%), renal colic $(33.91 \%)$ and hematuria $(9.01 \%)$. The main anatomical location was bladder $(62.23 \%)$. The management was essentially medical and surgical. We recorded 7 cases of death or post-interventional hospital mortality rate of $3 \%$. Conclusion: Urolithiasis is a real public health problem in Chad. Due to the inadequacy of the technical platform, the management was based on the open surgery. Etiological research was impossible by lack of technical laboratory platform.
\end{abstract}

\section{Keywords}

Urolithiasis, Nephrectomy, Cystolithotomy, Calculi 


\section{Introduction}

Urolithiasis is the presence of one or more stony concretions located at any level of a segment of the urinary tract (calyx, renal pelvis, ureter, bladder and urethra). It is also a pathology as old as the world, readily recurrent [1] [2]. The examination of Egyptian mummies by British archaeologists in 1901 on the burial site of El Amra, helped highlight bladder and kidney stones dating from antiquity [3]. The factors of stone disease namely the warm climate, dietary animal protein (milk, egg, meat), urinary infection, urinary malformations pathologies, trauma of the pelvis and lower urinary tract obstacles are frequently found at examination of patients in urology. Lesional and topographic diagnosis of urolithiasis is nowadays facilitated by the particular ultrasound imaging by its non-invasive nature and the possibility of repeating. The management is revolutionized by the advent of urological endoscopy, laparoscopy and lithotripsy [4] [5]. However, the open surgery remains a better alternative in less medicalized countries [6] [7].

The purpose of this study was to determine the epidemiological, clinical and therapeutic of urolithiasis.

\section{Patients and Methods}

This was a descriptive type of a prospective study of 233 patients with urolithiasis in a total of 4072 patients seen for consultation in urology department.

Patients, of any age and any gender confused, came from N'Djamena, from inside the country and sometimes from neighboring countries. These patients were consulted directly in urology department or were referred from peripheral centers. Were selected all patients consulted in the urology department, in whom the diagnosis of urolithiasis was placed after paraclinical assessment, supported and monitored in the urology department. Were excluded all patients without paraclinical assessments confirming the diagnosis, those whose care was made outside of urology department and those with stones located outside the urinary tract. The reasons for study were explained to the patients, their parents (for minors) and their consent as their medical records files will be anonymously used for science was obtained. Data were collected and analyzed using SPSS 18.1 and mean and frequency calculations were performed. The ethics committee of the National Order of Physicians of Chad gave its approval before the start of this study.

The variables considered were:

- Epidemiological: age, sex, predisposing factors (region, residence, source of water, amount of water consumed and diet).

- Clinical: dysuria, renal colic, urinary retention, urinary burning, urinary frequency, hematuria, urinary urgency, history (bilharzia, chlamydia, gonorrhea...)

- Paraclinical: Imaging (abdomen without preparation, intravenous urography, radiograph of the pelvis, ultrasonography), urine culture, creatinine, serum calcium, serum uric acid.

- Treatment: medical treatment (water diet, analgesic, antipyretic, anti-inflammatory) and surgical (nephrolithotomy, nephrectomy carrying out the stones, ureterolithotomy, cystolithotomy, urethrolithotomy;

- Evolutionary: healing, complications and deaths.

All operated patients were regularly followed in urology, every three months over a period of two years after delivering their exeat. Control was provided by radiography which revealed no postoperative urinary stone.

\section{Results}

The average age of patients was 36 years, ranging from 15 months to 88 years. With a staff of 67 cases or $28.77 \%$ of urolithiasis, the age group 0 - 10 years is the most represented, followed by $11-20$ years and 51 - 60 years (Table 1). Youth 0 - 20 years are most frequently holders of secondary urethral calculi to complications of circumcision. Table 2, Figures 1-3 show the relationship between age and location of the stones. For each age group, the male patients were significant with a sex ratio of 4.5. The distribution by age and sex also shows a male predominance (Figure 4). The socioeconomic level seems to be a predisposing factor to the development of urolithiasis ( $\mathrm{n}=122$ or $52.36 \%)$. The stones affected: school students and university students ( $\mathrm{n}=64$ or $27.47 \%$ ), non-professionals ( $\mathrm{n}=40$ or $17.17 \%$ ) and middle public officials ( $\mathrm{n}=36$ or $15.45 \%$ ). The water from traditional wells was used by 91 patients, 110 patients consumed less than one liter of water. Figure 5 reports the different reasons for consultation. Urolithiasis $(n=17)$ and urogenital bilharzia $(n=11)$ were found as medical history. The patients diet was rich in meat $(n=200)$, milk $(n=160)$, fish $(n=150)$ and eggs $(n=130)$. 
Table 1. Distribution of patients according to age groups.

\begin{tabular}{ccc}
\hline Age groups (years) & Effectives & $(\%)$ \\
\hline $0-10$ & 67 & 28.77 \\
$11-20$ & 35 & 15.02 \\
$21-30$ & 32 & 13.73 \\
$31-40$ & 23 & 9.87 \\
$41-50$ & 20 & 8.58 \\
$51-60$ & 33 & 14.16 \\
$61-70$ & 17 & 7.29 \\
$71-80$ & 4 & 1.71 \\
+80 & 2 & 0.85 \\
Total & 233 & 100 \\
\hline
\end{tabular}

Table 2. Distribution of stones according to age groups and the location.

\begin{tabular}{ccccc}
\hline Age groups (years) & Nephrolithiasis & Ureteral calculi & Bladder lithiasis & Urethral calculi \\
\hline $0-10$ & - & $1(0.86 \%)$ & $57(24.46 \%)$ & $9(3.86 \%)$ \\
$11-20$ & $12(5.15 \%)$ & $2(0.86 \%)$ & $19(8.15 \%)$ & $2(0.86 \%)$ \\
$21-30$ & $14(6.01 \%)$ & $6(2.57 \%)$ & $12(5.15 \%)$ & - \\
$31-40$ & $12(5.15 \%)$ & - & $10(4.29 \%)$ & $1(0.43 \%)$ \\
$41-50$ & $9(3.86 \%)$ & $4(1.72 \%)$ & $6(2.57 \%)$ & - \\
$51-60$ & $9(3.43 \%)$ & $2(0.86 \%)$ & $22(9.44 \%)$ & $1(0.43 \%)$ \\
$61-70$ & $2(0.43 \%)$ & - & $3(1.29 \%)$ & - \\
$71-80$ & $1(0.43 \%)$ & - & $2(0.86 \%)$ & - \\
\hline
\end{tabular}

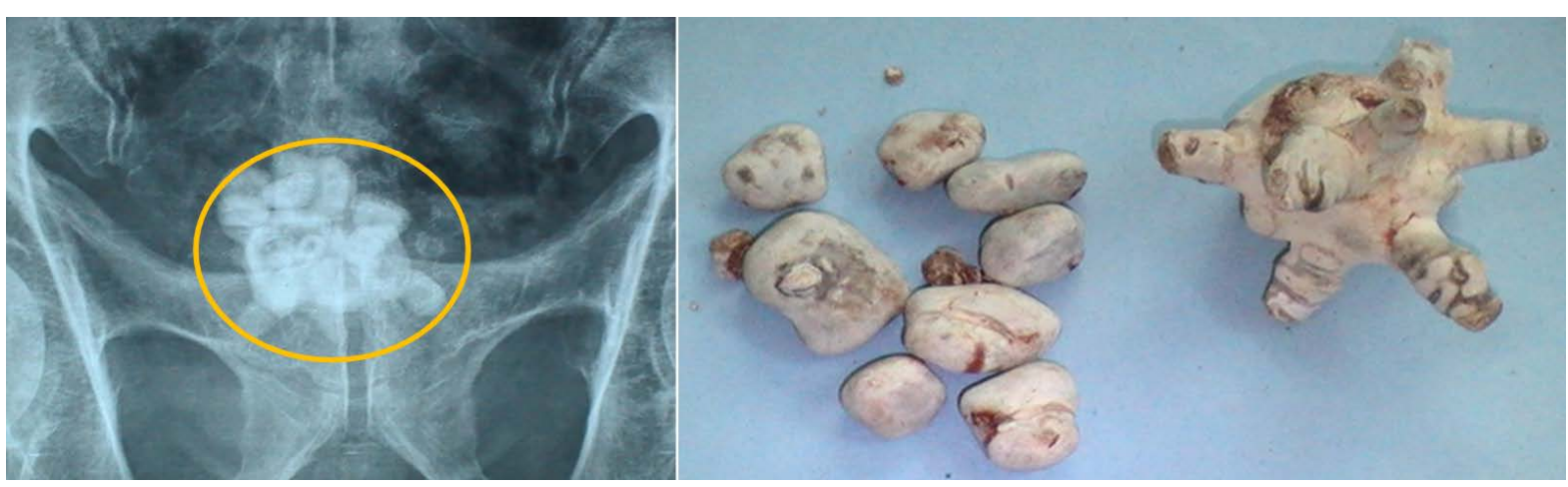

Figure 1. Bladder lithiasis on pelvic radiography without preparation (left, surrounded) and stones collected after cystolithotomy (right). 


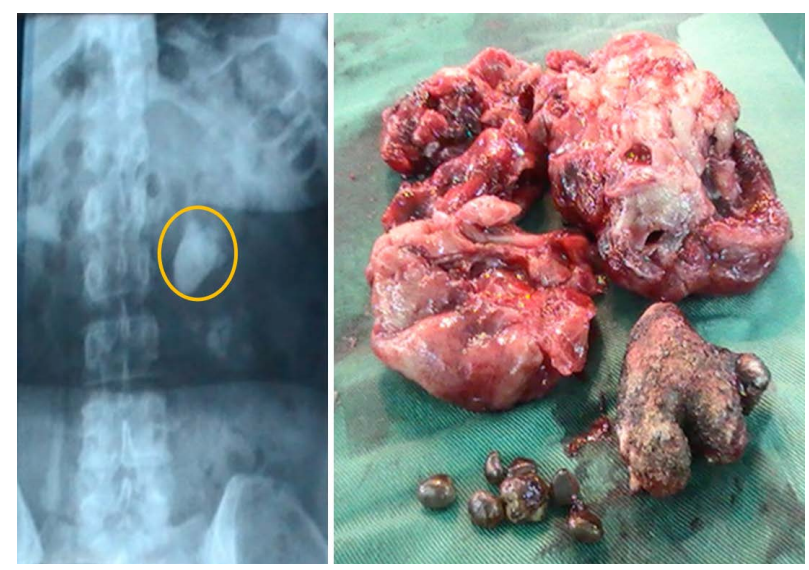

Figure 2. Nephrolithiasis in abdominal radiography without preparation (left, surrounded) and total nephrectomy carrying out the stones (right).

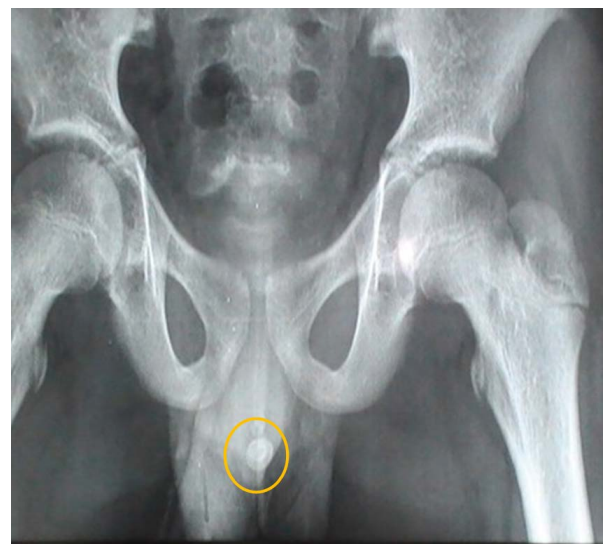

Figure 3. Urethal lithiasis, surrounded.

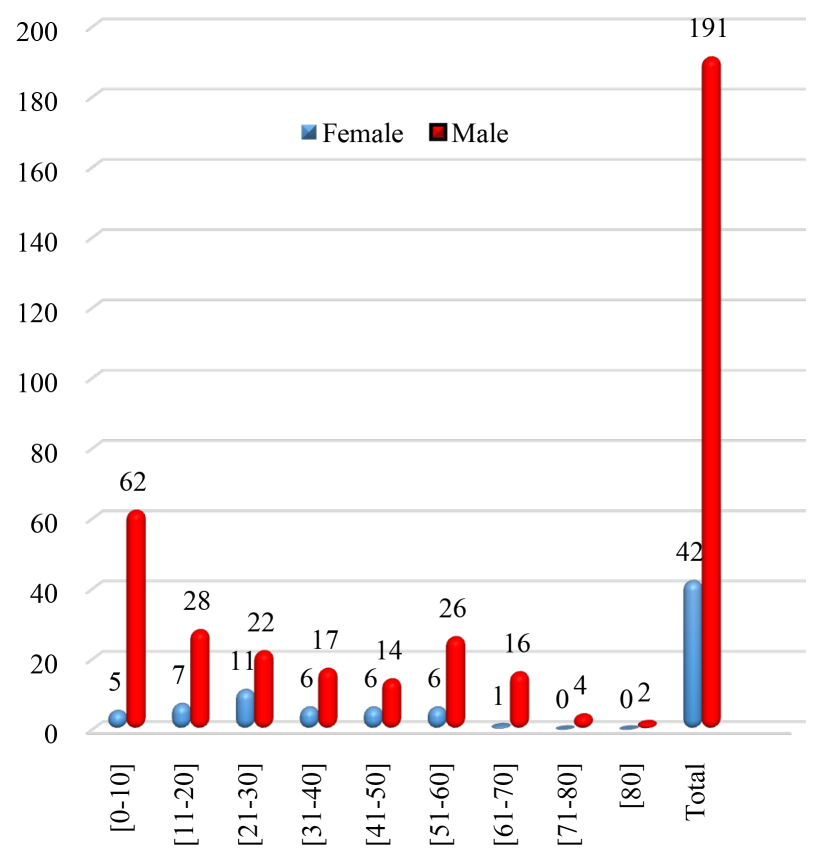

Figure 4. Distribution of patients according to age groups and sex. 
Paraclinical explorations used: ultrasonography in 181 patients or $55.7 \%$, followed by the intravenous urography ( $n=66$ ), radiography of the pelvis without preparation $(n=63)$ and radiography of the abdomen without preparation $(n=15)$. From 233 patients whom has done urine culture, 83 showed calcium oxalate crystals and a high rate of serum calcium. All patients were subjected to: the liquid diet with absorption of at least 2 liters of water per day for adults, an anti-inflammatory and a triple antibiotic therapy in case of associated fever. During the crisis of renal colic, liquid restriction was recommended. The most practised surgery was cystolithotomy with 152 cases or $65.23 \%$ of procedures (132 cases of simple cystolithotomy, 19 cases of prostatectomy + cystolithotomy and 1 case of cystolithotomy + nephrolithotomy), followed by nephrolithotomy, renal pelvis lithotomy and nephrectomy carrying out the stones (Table 3 ). The aftermath of the surgery was simple, except for 2 cases of postoperative bleeding, 2 cases of suppuration of the wound, 7 cases of deaths recorded.

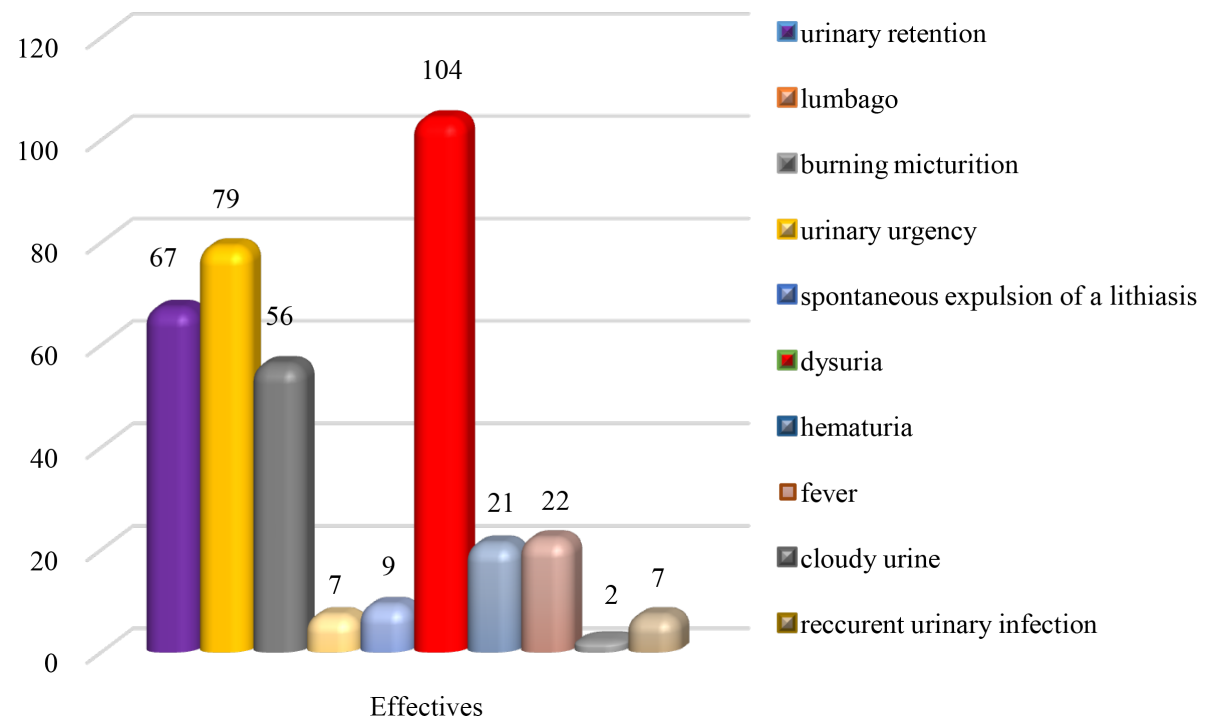

Figure 5. Distribution of patients depending on the reasons for consultation.

Table 3. Distribution of patients according to the surgery type.

\begin{tabular}{ccc}
\hline Surgery type & Effective & $(\%)$ \\
\hline Nephrolithotomy & 27 & 11.59 \\
Pelvic renal lithotomy & 20 & 8.58 \\
Nephrectomy & 11 & 4.72 \\
ureterolithotomy & 14 & 6.01 \\
Cystolithotomy & $\mathbf{1 3 2}$ & $\mathbf{5 6 . 6 5}$ \\
Cystolithotomy + prostate adenomectomy & 19 & 8.15 \\
Cystolithotomy + Nephrolithotomy & 1 & 0.43 \\
Urethral lithotomy & 7 & 3.00 \\
urethroplasty & 1 & 0.43 \\
manual removal & 1 & 0.43 \\
Total & $\mathbf{2 3 3}$ & $\mathbf{1 0 0}$ \\
\hline
\end{tabular}




\section{Discussion}

Our study reported 233 cases of stones operated over a period of four years. During the same period, 3015 surgeries were performed. Urolithiasis represents $7.73 \%$ of surgical service and occupies the second place after prostate prostatectomy.

The predominance of the male sex was significant. The stones on male predilection field sat on the lower urinary tract were related to complications of circumcision, the valves of the posterior urethra and congenital stenosis of the urethra younger. In elderly male subjects, stone complicated urethral strictures consecutive urethritis with chlamydia to urogenital schistosomiasis, in benign prostatic hyperplasia. To these predisposing factors for stone disease in the subject male, must be added the greater length of the male urethra exposing the trauma. Several African studies incriminate bilharzia in lithogenesis [1] [8]-[10]. Urinary schistosomiasis is a parasitic disease that is endemic in Central Africa, particularly in Chad. It is caused due to a trematode belonging to the schistosomidae family and gender Schistosoma haematobium. After mating in the liver, adult worms migrate in the splanchnic vessels to lay eggs. Induced inflammatory reaction causes schistosomiasis fibrosis causing stenosis (urethral, ureteral) and the little bit sclerotic bladder compliant slowing the flow of urine thereby promoting, infection and the formation of stones. Furthermore, calcified eggs urinary schistosomiasis serves as cores around which will aggregate of crystalline components and the starting point of lithiasis in a urinary cavity.

Table 4. Change in clinical symptoms according to studies and countries.

\begin{tabular}{|c|c|c|c|c|c|c|c|c|}
\hline & $\begin{array}{c}\text { Our study } \\
\text { (\%) }\end{array}$ & $\begin{array}{c}\text { Hounnasso, } \\
2015,102 \\
\text { cases (\%) }\end{array}$ & $\begin{array}{c}\text { Odzebe } \\
2015,71 \\
\text { cases (\%) }\end{array}$ & $\begin{array}{c}\text { Kaboré, } \\
\text { 2013, } 450 \\
\text { cases (\%) }\end{array}$ & $\begin{array}{c}\text { Coulibaly, } \\
2011,23 \\
\text { cases (\%) }\end{array}$ & $\begin{array}{c}\text { Sow, } 2010 \\
\text { (\%) }\end{array}$ & $\begin{array}{l}\text { Odzebe, } \\
2010 \text { (\%) }\end{array}$ & $\begin{array}{c}\text { Bah, 2009, } \\
111 \text { cases } \\
\text { (\%) }\end{array}$ \\
\hline Obstructive anuria & - & 7.8 & - & - & - & - & - & - \\
\hline Burning urination & 24.03 & 17.6 & 5.2 & - & - & 10 & - & - \\
\hline Renal colic & - & 79.4 & 9.4 & 32.7 & 30.4 & - & 15.3 & - \\
\hline Febrile renal colic & - & 14.7 & - & - & - & - & - & - \\
\hline Abdominal pain & - & & - & - & - & - & 18.4 & - \\
\hline Hypogastric pain & - & - & 15.1 & & 13.04 & 4 & & 47 \\
\hline Pelvic pain & - & - & - & 32.6 & - & - & - & - \\
\hline Dysuria & 44.63 & 17.6 & 18.4 & 31.6 & 17.4 & 12 & 15.3 & 44 \\
\hline Spontaneous expulsion of stone & 3.86 & - & & 11.1 & - & - & - & - \\
\hline Fever & 9.44 & - & 14.6 & 3 & 56.5 & - & - & - \\
\hline Hematuria & 9.41 & 15.7 & 5.8 & & - & - & 15.3 & 17 \\
\hline Urinary urgency & 3 & & - & & - & - & - & - \\
\hline Reccurent urinary infection & 3 & 6.9 & - & 6.2 & - & - & - & - \\
\hline Lumbago & 33.9 & 41.2 & - & 84.1 & 26.08 & 3 & - & - \\
\hline Nausea/vomiting & - & 14.7 & - & - & - & - & - & - \\
\hline Pollakiuria & - & - & 2.3 & & 4.3 & 4 & 9.2 & 42 \\
\hline Pyuria & - & - & - & - & - & - & - & 8 \\
\hline Acute urinary retention & 28.75 & - & 13.6 & 2.2 & 9 & 4 & 26.5 & 34 \\
\hline Cloudy urine & 0.8 & - & - & - & - & - & - & - \\
\hline
\end{tabular}


It appears from our study that no age is spared from urolithiasis, demonstrating sufficiently that the formation of the stones depends on the contributing factors, the crystal supersaturation and deficit in lithogenesis inhibitors. However the location of the stones varies by age. Urethral and bladder lithiasis is the prerogative of the young child, ureteral and renal stones are the prerogative of the adult while urolithiasis complicates the enlarged prostate for patients in their sixties. The inaccessibility to clean water, ignorance of the rules of hygiene is all contributing factors to the outbreak of urolithiasis in our study population. It appears that patients consume less than 1.5 liters of water per day in Chad, a country where he averaged fact, an ambient temperature of $45^{\circ} \mathrm{C}$ in the shade during the hot periods of the year (February to June). The diet is high in animal protein (milk, egg, meat and fish) because Chad is a country farm. It appears from the examination of the urinary sediment as calcium oxalate crystals were found in 83 patients who also had high serum calcium. These were the farmers whose diet is based on milk. All contributing factors of lithogenesis gathered for the development of stones in our study population.

Clinical symptoms vary between studies and countries as highlighted in Table 4 [1] [6] [7] [10]-[13].

Para examinations most used clinical, ultrasound confirmed the diagnosis of urolithiasis and its topography and its impact on the upper urinary tract. The anodyne nature of ultrasound, the ease of its execution, the possibility of its repetition, make of the ultrasound a choice examination for the diagnosis of urolithiasis when performed by expert hands.

However the chemical analysis of the stones is not made due to lack of infrared spectrophotometry limiting lifestyle advice to provide to patients.

The gold standard of treatment of urolithiasis is arguably today lithotripsy, endourology and laparoscopy when the technical platform allows.

Because of the inadequacy of the technical platform, the open surgery is the only alternative that allows us to take care of all our patients. Open surgery should always be taught to young urologists for patient safety when modern techniques require conversion.

\section{Conclusions}

Urolithiasis is a common disease worldwide and particularly in Chad. With 233 patients treated in the urology department of the HGRN, urolithiasis is the second main cause of surgery. The male is the most achieved. The most affected age group is that of 0 - 10 years. The main etiologies and predisposing factors are represented by urinary tract infections, urogenital schistosomiasis, the diet rich in calcium, etc. The main symptoms are represented by dysuria, renal colic, the micturition burns, etc.

Paraclinical diagnosis is mainly based on ultrasound and IVU. By lack of technical facilities, treatment is based on the open surgery. The prevention of urolithiasis goes through the eradication of schistosomiasis, the treatment of sexually transmitted infections, nutrition education and physicochimical analysis of stones to provide a better nutritional advice.

\section{References}

[1] Kaboré, F.A., Kambou, T., Zango, B., Ouattara, A., Simporé, M., Lougué/Sorgho, C., et al. (2013) Epidemiology of a Cohort of 450 Urolithiasis at the Yalgado Ouédraogo University Hospital of Ouagadougou (Burkina Faso) (Épidémiologie d'une cohorte de 450 lithiases urinaires au CHU Yalgado Ouédraogo de Ouagadougou (Burkina Faso)). Progrès en Urologie, 23, 971-976. http://dx.doi.org/10.1016/j.purol.2013.04.014

[2] López, M. and Hoppe, B. (2010) History, Epidemiology and Regional Diversities of Urolithiasis. Pediatric Nephrology, 25, 49-59. http://dx.doi.org/10.1007/s00467-008-0960-5

[3] Shah, J. and Whitfield, H.N. (2002) Urolithiasis through the Ages. British Journal of Urology, 89, 801-810. http://dx.doi.org/10.1046/j.1464-410X.2002.02769.x

[4] Tawfiek, E.R. and Bagley, D.H. (1999) Management of Upper Urinary Tract Calculi with Ureteroscopic Techniques. Urology, 53, 25-31. http://dx.doi.org/10.1016/S0090-4295(98)00462-2

[5] Hecht, S.L. and Wolf, J.S. (2013) Techniques for Holmium Laser Lithotripsy of Intrarenal Calculi. Urology, 81, 442445. http://dx.doi.org/10.1016/j.urology.2012.11.021

[6] Odzebe, A.S.W., Bouya P.A., Berthe H.J.G. and Omatassa F.R. (2010) Open Surgery of the Urinary Tract Calculi at the University Hospital of Brazzaville: Analysis of 68 Cases. Mali Medical, 25, 32-35.

[7] Odzebe, A.W.S., Bouya, P.A., Koutaba, E., Mandavo, C., OndzelOpara, A.S., BoussoukouNzikou, V., et al. (2015) 
Urolithiasis in Children at the University Hospital of Brazzaville. Uro’Andro, 1, 183-187.

[8] Zoung-Kanyi, J. and Sow, M. (1990) The Urinary Lithiasis in Cameroon Etiopathogenic Considerations, Clinical and Therapy, about 118 Cases (La LithiaseUrinaire Au Cameroun Considerations Etiopathogeniques, Clinique Et Therapeutique. A propos de 118 cas.). Médecine d'Afrique Noire, 37, 176-182.

[9] Ouattara, Z., Effoe, A., Temberly, A., Sanago, Z.Z., Yena, S., Doumbia, D., et al. (2004) Study of 72 Cases of Upper Urinary Tract Calculi in Urology Department at Point "G” Hospital (Etude de 72 cas de lithiase du haut appareil urinaire au service d’urologie de l’hôpital du point “G”). Mali Médical, 19, 14-17.

[10] Coulibaly, Y., Ouattara, Z., Togo, A., Konate, M., Ouattara, M. and Ouattara, K. (2011) Bilharziasis and Urinary Lithiasis: A Study of 23 Cases at the Gabriel Toure Hospital (Bilharzioseurinaireetlithogenese: Etude de 23 cas au CHU Gabriel Toure). Mali Médical, 26, 26-28.

[11] Hounnasso, P.P., et al. (2015) Symptomatic Urinary Lithiasis: Epidemiology and Management at Urology Department of University Hospital of Cotonou. Open Journal of Urology, 5, 7-12. http://dx.doi.org/10.4236/oju.2015.52002

[12] Sow, Y., Coulibaly, M., Fall, B., Sarr, A., Fall, P.A., NDoye, A.K., et al. (2010) Urinary Lithiasis in Children: A 20 Cases Study. Mali Médical, 25, 43-46.

[13] Bah, I., Diallo, A.B., Diallo, A., Bah, O.R., Barry, K., Kanté, D., et al. (2009) The Lower Urinary Tract Calculi: Retrospective Analysis of 111 Cases at the University Hospital of Conakry (La lithiase du bas appareilurinaire: Analyserétrospective de 111 cas au CHU de Conakry). African Journal of Urology, 15, 38-43. http://dx.doi.org/10.1007/s12301-009-0008-5 